\title{
The Roots of Philosophy of Chomsky's Transformational-Generative Theory
}

\author{
Hanan Mashaqba \\ Doctorate Degree Candidate in Philosophy \\ University of Jordan
}

\begin{abstract}
This study attempts to shed light on the philosophical roots that the American philosopher and linguist Noam Chomsky relied on in building his linguistic theory called the Generative Transformational Theory, the theory through which he wanted to take the study of language a new direction in which he exceeds all the experimental explanations of the linguistic phenomenon. Chomsky tried to establish his linguistic theory by discussing the rational innate hypothesis of the German philosopher Wilhelm Humboldt, the Greek philosopher Plato, and the French philosopher René Descartes, as their innate hypotheses had a great influence on Chomsky's study and understanding of the linguistic phenomenon. Chomsky has posed several questions that are closely related to the epistemology of every philosopher of the past, and each question raised a specific problem that required Chomsky to present a solution to it, and this solution was based on the same premise.
\end{abstract}

\section{Introduction}

Chomsky added a kind of philosophical understanding in his study of the linguistic phenomenon, as he invoked the approaches that prevailed in the study of language, those approaches that follow the experimental scientific method that makes experience only a criterion for judging the truth of knowledge or its falsehood, and from here Chomsky revived the ancient European tradition that depends on the deductive approach in the interpretation of facts, taking from the philosophical rationale doctrines a basic point from which to base the interpretation of the linguistic phenomenon.

Thus, the philosophical understanding of the linguistic phenomenon is more evident here by indicating that the phenomenon of language acquisition and the ability to produce an infinite number of linguistic structures creatively does not come through learning as indicated by Skinner's psychological theory (Kwan, 2008: 101), as indicated by linguistic theories influenced by empirical doctrines such as Sauusure's structural theory (Sauusure, 1958) and Bloomfield's behavioral theory (Bloomfield, 1933), which were based on experimentation and induction, but through the innate rational hypothesis.

After a century of denouncing and rejecting empirical doctrines, rational doctrines in the interpretation of the linguistic phenomenon, however, the rational approach that represents the rational doctrines - which explains the linguistic phenomenon through the innate hypothesis - has returned again through the transformative generative theory that mainly discusses generative grammar as an innate linguistic faculty.

This shows that there is an articulated shift regarding the study of the linguistic phenomenon in Chomsky, where the study shifted from an interest in the verbal behavior of the speakers by adopting experimental scientific approaches to an interest in studying the mind - the brain influenced by rational philosophers, namely Wilhelm Humboldt, Plato and René Dysart who took a rational approach in explaining everything related to language,this means rejection of inductive approaches versus the adoption of deductive approaches in the study of language by Chomsky. Whereas the interest in verbal behaviour was subject to measurement and experience, the interest became focused on saying that there are innate principles or a holistic approach responsible for producing language.

\section{Previous Literature}

Darqawi (2014) study seeks to introduce the theory of effective lesson lingual talk, a linguistic theory of Chomsky, which revolutionized changed the map of thought in the second half of the last century, providing the perceptions of new knowledge is based on in-depth requirements psychological speaker creative, and inspired the mind is the frame of reference Select which Chomsky and his point of view on the issue of language acquisition, which can only be achieved according to two principles are the linguistic competence and performance.

Multiple studies have been conducted in Chomsky's linguistic philosophy dealing with the philosophical foundations on which the generative, transformational theory was based, among these studies is a study by Michael Root (1970) in which he presented Chomsky's view that linguistics has an effective influence regarding the problem of innate ideas, because the information obtained from language provides us with reasons to accept the claim of rationalists that there are ideas that can have a role in the educational mission, this model consists of an acquisition tool that has an internal structure that is able to provide us with an understanding of the way in which a child learns language (Root, 1970). 
In another study by Benkirane Ahmed al-Tayeb (1997) he referred to what Chomsky called the Plato problem, which relates to the philosophical problem that raises the question of how human beings can access multiple knowledge despite their limited contact with the world. Plato's conception of this problem was to say that we do not acquire new knowledge but only re-discover knowledge previously given to us (Al-Tayeb, 1997).

Another study entitled Cartesian linguistics dealt with Descartes' innate theory of ideas and how this theory has a reflection on the subject of language, and thus Chomsky affects this hypothesis (Behme, 2001).

\section{The Study Problem}

The problem of the study lies in tracing the philosophical roots of Chomsky's generative grammar theory and has Chomsky actually managed the philosophical rooting of this theory and thus has the theory actually been able to explain how language is acquired and produced creatively.

\section{The Importance of the Study}

The importance of this study is highlighted in that it demonstrates the mental tendency of generative grammar by revealing the concept of innate ideas that contain some differences between rational philosophers and how these ideas formed the philosophical basis for Chomsky in building his generative transformative theory, and what this study is trying to do is an illustration in it, which is a kind of totalitarianism covering the concept of innate hypothesis.

\section{Objectives of the study}

Accordingly, the objectives of this study are to investigate the philosophical roots of Chomsky's linguistic theory, by linking it with epistemology. It is necessary to be able to clarify how Chomsky's theory was able to overcome all previous theories in understanding the linguistic phenomenon by addressing Plato's epistemology in Greek philosophy, and Descartes' epistemology in modern philosophy, in addition to dealing with Wilhelm Humboldt's position on the language phenomenon, in order to reach their relationship to the linguistic phenomenon of Chomsky.

\section{Philosophical roots of Chomsky's linguistic theory}

In his construction of the transformative generative theory, Chomsky posed three questions that are directly related to epistemology that investigates "the principles, nature, and source of human knowledge, and its value and its limits, and in the relationship between Self-conscious and the perceived object (Al-Sokari, 1999: p.27)) and the philosophical views associated with it, especially those opinions which the advocates of the innate theory, i.e. the owners of the rationalist doctrine against the owners of the empirical doctrine believe, as each question was associated with a philosopher, as each question revealed the philosophical foundations of the generative theory of Chomsky, and these questions are: (Chomsky, 1993):

1. What does knowledge of language consist of?

2. How do you gain knowledge of the language?

3. How do you use language knowledge?

These three questions are closely related to the development of the theory of knowledge with a rational tendency, and it will be explained here how each of them discusses one of the theories: the theory of recollection in Plato, the theory of innate ideas in Descartes, and the theory of the built-in language of Humboldt. The first question is related to "What does knowledge consist of?" with the German philosopher Humboldt, the second question, "How is knowledge acquired?" With the Greek philosopher Plato, while the third question, "How is knowledge produced?" By the French philosopher René Descartes.

\section{The Humboldt Problem}

The first question is related to "What does knowledge consist of in a language?" One of the classic formulations of the definition of language, presented by one of the philosophers of the nineteenth century, the philosopher and linguist Humboldt, who says: "Language is a system that provides unlimited use of limited means" (Chomsky, 1991:7).

Humboldt tried to override the idea that the difference in languages is a difference on the surface or the external form of the language, i.e. on the level of signs and phonemic structures. There is even something further than that, as he pointed out the existence of two forms of the language, the first is the internal form and the second is the external form (Al-Sayed, 1989: 53-54).Consequently, the deeper thinking of language from Humboldt's point of view must be towards the internal form of language, or the deep structure of language, that form that comes from within the human being, i.e. from his mind as language is immanent to the human nature on the one hand, and which is responsible for the diversity of languages on the other hand. 
But how is the deep structure of a language the source of the diversity of languages and how is it immanent to human nature that makes creativity a function of language? This is through implicit mental rules inherent in the mind, those rules are generative, innate, renewable, as "the mental strength that provides us with the faculty of speech assumes the existence of a system of generative rules that organizes the work of the linguistic queen and forms the ground for its expression. This system is a generative system; simply because it creates unlimited uses of limited mediums (Al-Harees 2018: 33).

From the foregoing it becomes clear that Humboldt explains the creative aspect of language by the presence of innate generative mental rules present in the mind, but the assumption presented by Humboldt is not sufficient for the purpose, as how does language exist in the mind and how is it generated? Chomsky solved Humboldt's problem by saying that there is a linguistic faculty present in an organ called the language organ located in the brain, where he said, "The first of these assumptions is the existence of a linguistic faculty, meaning that there is a part in the mind - the brain dedicated to knowledge and the use of language. This is a specific function of the body, which is more like a linguistic organ, almost identical to the visual apparatus that is also dedicated to a specific task. " (Chomsky, 2017: 26).

Where this organ contains a language called the built-in language, which refers to the deep structure of the language, that structure that contains implicit rules responsible for the creative appearance of language, as Chomsky said that the internal structure is "some elements of the human brain of a person who knows the language, acquired from the learner and used." Who spoke it and listened to it" (Chomsky, 1968: 22)? From the above, we can say that Chomsky proceeded from the innate hypothesis to put the theory of deep structure as a solution to the Humboldt problem.

\section{Plato's Problem}

Plato had a very great influence with regard to Chomsky's linguistic theory, through what was known as Plato's problem, who saw that there is no balance between the ideas that we produce and the knowledge that we obtain, and this Plato idea or problem made Chomsky raise the following question: "How can we know this very large amount, given that what we have to evidence is of a very specific kind?" (Chomsky, 1993: 43).

Plato / Socrates clarified this problem through the Menon dialogue, whereby Socrates posed a series of questions related to geometry to a young Mumluk who had not received any education regarding the principles of geometry with the aim of making the young Mumluk discover proofs of engineering himself, and this is what really happened where the young man was able to reveal these principles himself, and this is what made Menon know clearly that this young man's ideas were latent in him and out of him himself without receiving any education(Al-Sokari, 1999: 46).

This is what made Plato assert that our knowledge is innate and that it necessarily precedes sensory experience and this is evident through his solution to this problem, where he clarified that knowledge was present by force in the mind of the owner. And that what Socrates did nothing more than awaken this knowledge from its latitude, and make the Mumluks remember it through the questions directed to him. (Chomsky, 1990: 15).

The stimulation of the knowledge latent in us means, from Plato's viewpoint, the stimulation of the knowledge that is latent and present by force in our souls, through what Plato called the theory of remembrance, according to which our souls possess knowledge in a time prior to the time of their arrival in the body. (Plato, 2003: 144).

Chomsky tried to apply Plato's problem in terms of knowledge to his study of the linguistic phenomenon, as Chomsky believes that our knowledge is the result of certain innate characteristics "These characteristics are similar to the elements of our common nature that make it necessary for us to grow legs and arms instead of wings" (Chomsky, 1990: 16). Chomsky explained this through the holistic grammar theory that he derived from the innate hypothesis as a solution to Plato's problem, according to which the language organ contains a device called the language acquisition apparatus that contains the total rules responsible for our innate knowledge in general and children's knowledge in particular of language, in Chomsky's view, overall grammar is "general language attributes that reflect a kind of biological necessity rather than a logical necessity, that is, the qualities of the language that are not logically necessary for such a system, but rather the intrinsic, qualities of the human language that are known without learning "(Chomsky, 2010: 88-89).

The overall rules have innate origins and thus constitute the common denominator between all people, regardless of their races and countries, and between all human languages, this is what Michel Zakaria expressed:"The universal rules contain the universal principles that are jointly established within the sufficiency of the speaker of any language, it is a picture expressing the essence of the human language, and it contains the permanent, constant and existing principles within the human mind, which are unchanging for the diversity of the human race"(Zakariah, 1993: 69). 


\section{Descartes's problem}

Descartes's basic theory was a theory of knowledge and methods of reaching it, and it was not a direct theory of language, as Descartes did not have clear perceptions of language, and therefore it is necessary to present his main idea from his theory of thought in order for us to extract his position on language.

Descartes wanted his epistemological theory to be based on certainty foundations quite similar to those foundations on which the mathematical sciences were based, which are characterized by absolute certainty (Descartes, 1991: 23). Therefore, he considered that innate ideas are absolutely certain ideas as they are "intuitive ideas that every sane person believes because they do not raise any doubt about their validity, and these ideas are like, the idea of the cogito and the whole is greater than the part, the existence of the soul, the existence of God, and the external world " (Fadluallah, 1986:113).

He explained that what distinguishes humans from animals is the ability to think, and there must be a tool for expressing ideas and this tool is language expressions, and therefore the main focus of the ability to use language words is thinking. Despite the ability of animals to pronounce some words, they are unable to produce language because they do not have ideas that require the use of language to express them, unlike humans who have ideas and therefore use language to express them (Bin Noa'man, 1992: 95).

Descartes concludes by emphasizing the innateness of language, which is a quality that a person possesses only. Just as a person is born equipped with elementary principles and innate ideas that make him distinguish right from wrong during his acquisition of knowledge, he is also born equipped with language, which is also completely innate, just like innate ideas, as Descartes asserted that "language is an innate force in man, he was born equipped with it, it is limited to him as the only being capable of forming a specific system of words, linguistic sentences and signs that enable him to convey his thoughts and express it to others, which is what all other beings lack "(Faraj, 2008: 36).

Descartes' linguistic views had a great influence on contemporary philosophy, and in particular on Noam Chomsky, who saw that the nature of our knowledge of language is an innate nature, adopting the thought of Descartes, which distinguished between man and animals (Lyons, 1985: 256).

Whereas Descartes interpreted the creative appearance of language starting from the innate hypothesis based on the fact that the roll is inherent in nature because it expresses innate creative and certain ideas, Chomsky explained the creative appearance through the solution he presented to Descartes' problem, which was launched from the theory of innate ideas, but from another angle somewhat different from that related to the problem of Humboldt and Plato, which is the angle that is based on some of the foundations of the linguistic theory of Chomsky, namely verbal performance and linguistic competence.

\section{Conclusion}

We have shown the philosophical foundations on which Chomsky relied in his study of the linguistic phenomenon, as these foundations stemmed from a rationality based on the innate hypothesis and were represented by the rational philosophers Humboldt, Plato and Descartes.

While Humboldt emphasized that there are two forms of language, one internal and the other external, and that the internal form is the form that reflects the action of the mind in the sense that the mind is the one that produces language. The Greek philosopher Plato explained that there is an imbalance between the knowledge that we receive from the outside and the knowledge that we produce, he explained this through the theory of remembrance, which holds that our knowledge of facts is an innate knowledge. Descartes emphasized that innate ideas are certain ideas that do not accept doubt at all through his theory of knowledge, as he showed through his linguistic views that what distinguishes man from animals is the possession of man of thought and the inability of animals to him, and this explains the creative ability of man to use language.

We also showed through this study how Chomsky was able to reach solutions to the problems that were plaguing the innate hypothesis of each of these three philosophers: the Humboldt problem, the Plato problem and the Descartes problem, which was represented in the ideal way out of the innate theory in order to overcome these problems is in consideration of the presence of the language organ that is genetically located in the human brain and which qualifies a person to possess the faculty of language. It is through this linguistic faculty, which has the inner implicit ability to deal with language, and thus the creative form of language can be interpreted and interpreted through the theory of deep structure and thus can solve the Humboldt problem.

He also proceeded from his vision of the innate theory to develop a theory of total rules, which says that there are common rules between all members of the human race and between all languages, and these rules explain how language is acquired, thus setting a solution to Plato's problem. 
Through innate theory, it also enables him to explain how language is used by differentiating between linguistic competence and linguistic performance to explain the creative form of language and thus present a solution to Descartes' problem.

Accordingly, the solutions presented by Chomsky to each of the problems related to epistemology, which he used mainly to build his linguistic theory based on the premise, through which Chomsky explained the ambiguity that surrounded the linguistic phenomenon due to the inability of the linguistic theories that were taken from the experimental method as a basis for explaining how the language is acquired as well as the interpretation of the creative appearance of the language, as Chomsky showed that there is a mental truth underlying the linguistic phenomenon, which is contradicted by each of the linguistic ability, overall grammar, and language proficiency.

\section{References}

Al-Harees, NF. (2018).The Creative Appearance of Language, Cognitive- Approximate Approach. Journal of the Arabic Linguistics. Vol. 6, 26-59.

Al-Sayed, S. (1989). "Chomsky His Linguistic Idea and The Opinions of Critics in it. Qairo: Dar Al- Ma'arefa AlJamee'ia.

AL - Sokari, A'. (1999). "The Theory of the Knowledge from the Sky of Philosophy to the land of School". Qairo: Al- Dar Al- Masriyah Al - lobnaniah.

Al-Tayeb, BA. (1997). Philosophical Background in Generative Theory. The Journal of World of Thought.

Behme, C. (2011). Cartesian Linguistics: from Historical Antecedents to computational Modeling, PhD in philosoph, Dalhousie University ‘Halifax, Nova Scotia.

Bin Noa'man, A. (1992). Language and Culture in Invasion Condition. Journal of the Arabic Thought. Vol (70).

Bloomfield, L (1993).Language, Henry Holt, New York1993.

Chomsky, N. (2017). "The Architecture of Language". Beirut: Jadawel for publishing and translation and distribution.

Chomsky, N. (2010). "Things You Will Never Hear". Damascus: Dar Nainawe.

Chomsky, N. (1993). "Knowledge of Language its Nature, Origin, and Use". Cairo: Dar Al- Fiker Al Arabi.

Chomsky, N. (1991).'Linguistics and Adjacent Fields: A Personal View '. In Asa Kasher(ed.),The Chomskyan Turn:Generative Linguistics, Philosophy, Mathematics, and Psychology, Oxford: Blackwell, pp 3-25.

Chomsky, N. (1990). "Language and Problems of Knowledge". AL-Dar AL- Baida'a: Dar Tobqal

Chomsky, N. (1968). Language and Mind, Harcourt Brace and World, Inc., New York 1968.

Darqawi, M. (2014). Transformational Generative Theory of ChomskyFoundations and Concepts, The Academy for Social and Human Studies B / Department of Literature and Philosophy, Issue 12, pp. 3-12.

De Saussure, F. (1985). "General Science of Language." Baghdad: Dar Afaq Arabia. Descartes, R. (1991). Method Article. Algeria: Mofem for Publishing.

Faraj, S. (2008). The Nature of the Relationship between Language and thought. Libya: General Culture Council.

Fadluallah, M. (1986). "Descartes' Philosophy and Method". Beirut: Dar Al-Talea'h.

KWAN, Sui Chi.,Language, Reality and Daohood:An exercise in comparative philosophy, $\mathrm{PhD}$ in Philosophy, The Hong Kong University of Science and Technology, Hong Kong 2008.

Lyons, J. (1985). "Chomsky's Linguistics Theory". Alexandria: Dar Al- Ma'arefa Al- Jamee'ia.

Plato, (2003). "Fidon's Dialogue in the Immortality of the Soul". Cairo: Dar Qubaa' for publishing and distribution.

Root, M., The Implications of Recent Developments in Linguistics for the Doctrine of Innate Ideas, $\mathrm{PhD}$ in philosophy, Northwestern University, Michigan 1970.

Zakareia, M.(1993). "Applied Linguistic Issues". Beirut: Dar Al E'lm lel Malaieen.

Zakareia, M. (1983). "Linguistics (Modern Linguistics), Principles and Flags". Beirut: University Foundation for Studies, Publishing and Distribution. 